\title{
High-pole LED lighting system
}

\author{
Y.V. Trofimov, S.I. Lishik, V.V. Dolgushin, Y.V. Kernazhytski \\ The Republican Scientific and Production Unitary Enterprise "Center of LED and Optoelectronic Technologies of \\ National Academy of Sciences of Belarus", \\ 22, Logoiski Trakt, Minsk BY-220090, The Republic of Belarus \\ Corresponding author phone: (+37517)-281-13-35; e-mail: sergey.lishik@gmail.com; www.ledcenter.by
}

\begin{abstract}
Different kinds of design of the 25-meter high-pole LED lighting system with 16 or 9 LED Street Lights "Phoenix" mounted on its crown (corona) have been suggested. The crown consists of two tiers. Some luminaries ( 8 or 4 pcs.) are installed on the first tier at an angle $\alpha_{1}$, while the other half is on the second tier at an angle $\alpha_{2}$ relative to the horizon plane. Based on the lighting simulation results, optimal luminaire orientation angles were defined as $\alpha_{1}=30^{\circ}$ and $\alpha_{2}=50^{\circ}$, which provides uniform illumination of an area $100 \times 100 \mathrm{~m}$ by size with the average luminance level 9.25 lux.
\end{abstract}

Keywords: high-pole LED lighting system, LED Street Light.

Manuscript received 12.12.112; revised version received 06.02.13; accepted for publication 19.03.13; published online 25.06.13.

\section{Introduction}

As generally known, the LED luminaire market is quickly expanding, and light-emitting diodes take the leading place, superseding conventional light sources in such areas as lighting of office facilities, working areas, personal service rooms, motorways, roads, streets, etc. Nevertheless, in some fields, the LED application is still insufficient. In particular, the creation of the high-pole (over $20 \mathrm{~m}$ ) LED lighting installations designed for lighting parking areas, rail and tramway depots, with a larger than 0.5 hectare area, is of much interest now. It is known that at present, these projects are introduced by the Russian company "Svetlana-optoelectronica" [1] and the Chinese Shenzhen Bang-Bell Electronics Co., Ltd [2].

This paper is devoted to studying the technical facilities for making 25-meter LED lighting installations on the basis of LED Street Lights "Phoenix", mass produced by our company. The main requirements for developed lighting system are the middle average illuminance level that is not less than $4 \mathrm{~lx}$ for parkings [3], and $61 x$ for depots [3], the maximum to minimum ratio of illuminance for rail facilities, grounds, roads and driveways shouldn't exceed 15:1 (0.066 according to item 5.1.5 of Russian Industry Standard OST 32120$98[3])$.

\section{Results}

Before talking about results, it should be noted that all photometric calculations were done using the program DIALux v.4.10 based on ies-data file for the light with maintenance factor equal to 0.71 , which includes the luminous flux attenuation with time.

As a rule, most of high-pole LED lighting installations consist of the backup abutment (high pole) and the corona, on which the lights are mounted. In some cases, the mobile corona is used and that makes easier the maintenance of such installations. Depending on the design, it can be one-tier or multitier corona. The lights set on the tier number $i$ are mounted at an angle $\alpha_{i}$. 


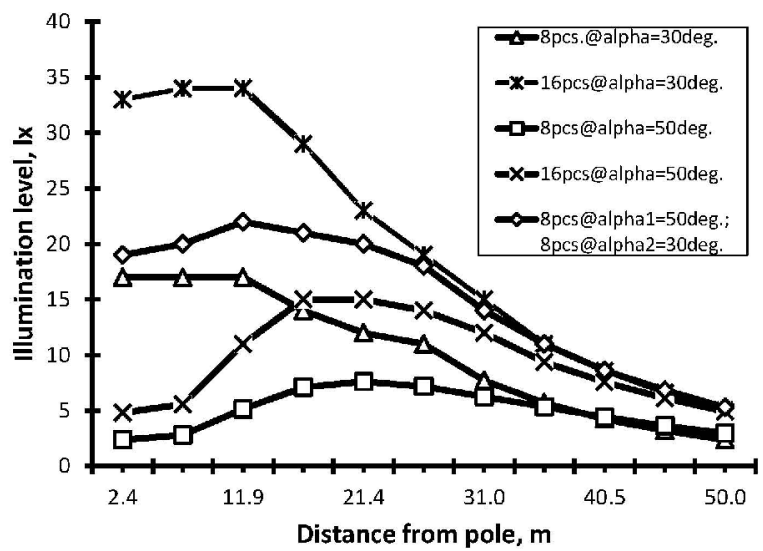

Fig. 1. Dependence of illumination on the distance to the highpole for different applications for corona of the high-pole lighting installation.

Let's examine one-tier corona and ascertain the influence of resulting photometric parameters of lighting system on the number $N$ and angle $\alpha_{1}$. The results of photometric calculations for $N=8$ units/16 units, as well as $\alpha_{1}=30^{\circ} / 50^{\circ}$ are presented in Fig. 1 .

As it follows from Fig. 1, the one-tier lighting system consisting of 8 LED lights, set at the angle $30^{\circ}$ to the horizon plane, doesn't provide a sufficient illumination level on the periphery of the illuminated surface, while simple increase in the number of LED lights from 8 to 16 units increases the maximum illuminance level $E_{\max }$ up to $34 \mathrm{~lx} / 15 \mathrm{~lx}$ and decreases the illuminance distribution non-uniformity index $E_{\min } / E_{\max }$.

In the case of the one-tier corona consisting of 8 lights set at the angle $50^{\circ}$ to the horizon plane, the main luminous flux is going to the remote area from the highpole installation position, while the maximum illuminance level $(8 \mathrm{~lx})$ is for $21-\mathrm{m}$ distance from the high-pole. Increasing the number of LED lights from 8 to 16 units results in increasing the middle illuminance level to $14 \mathrm{~lx}$, while the maximum illuminance level is shifted to the high-pole at the distance $17 \mathrm{~m}$ from the high-pole, and the illuminance non-uniformity is increased.

It's obvious that one-tier lighting installations in all the above mentioned applications don't meet requirements on the illuminance level and nonuniformity.

Now let's examine two-tier lighting installation. In this case, the resulting illuminance distribution is a superposition of illuminances from every tier and depends on tilt angles of lights on the first $\left(\alpha_{1}\right)$ and the second $\left(\alpha_{2}\right)$ corona tiers (Fig. 2). As follows from Fig. 1, the resulting illuminance distribution is more uniform, and the maximum illuminance level doesn't exceed $22 \mathrm{~lx}$.

Table. Dependence of the minimum to maximum ratio of illuminance $E_{\min } / E_{\max }($ a), the minimum to middle illuminance $E_{\text {min }} / E_{\text {mid }}\left(\right.$ b), the maximum illuminance $E_{\text {max }}\left(\right.$ c) and the middle illuminance $E_{\text {mid }}$ (d) on tilt angles on the first $\left(\alpha_{1}\right)$ and second $\left(\alpha_{2}\right)$ tiers (the parameters that don't meet requirements are filling with the black color; the given data are mirrored relative to the diagonal).

\begin{tabular}{|c|c|c|c|c|c|c|c|c|c|c|c|}
\hline & \multicolumn{10}{|c|}{ Tilt angle of lights on the second tier $\alpha_{2}$} \\
\hline & & $10^{\circ}$ & $15^{\circ}$ & $20^{\circ}$ & $25^{\circ}$ & $30^{\circ}$ & $35^{\circ}$ & $40^{\circ}$ & $45^{\circ}$ & $50^{\circ}$ & $55^{\circ}$ \\
\hline \multirow{10}{*}{ 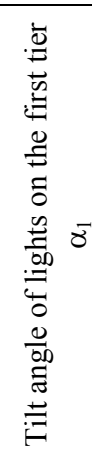 } & $10^{\circ}$ & 0.015 & 0.016 & 0.019 & 0.022 & 0.027 & 0.034 & 0.041 & 0.045 & 0.046 & 0.047 \\
\hline & $15^{\circ}$ & - & 0.017 & 0.019 & 0.023 & 0.028 & 0.036 & 0.044 & 0.048 & 0.049 & 0.049 \\
\hline & $20^{\circ}$ & & - & 0.022 & 0.025 & 0.032 & 0.041 & 0.051 & 0.056 & 0.057 & 0.058 \\
\hline & $25^{\circ}$ & & & - & 0.030 & 0.038 & 0.049 & 0.061 & 0.070 & 0.073 & 0.073 \\
\hline & $30^{\circ}$ & & & & - & 0.047 & 0.057 & 0.069 & 0.079 & 0.090 & 0.100 \\
\hline & $35^{\circ}$ & & & & & - & 0.064 & 0.076 & 0.088 & 0.101 & 0.111 \\
\hline & $40^{\circ}$ & & & & & & - & 0.086 & 0.098 & 0.110 & 0.121 \\
\hline & $45^{\circ}$ & & & & & & & - & 0.107 & 0.122 & 0.131 \\
\hline & $50^{\circ}$ & & & & & & & & - & 0.131 & 0.142 \\
\hline & $55^{\circ}$ & & & & & & & & & - & 0.161 \\
\hline
\end{tabular}

\begin{tabular}{|c|c|c|c|c|c|}
\hline & \multicolumn{4}{|c|}{ Tilt angle of lights on the second tier $\alpha_{2}$} \\
\hline & & $40^{\circ}$ & $45^{\circ}$ & $50^{\circ}$ & $55^{\circ}$ \\
\hline \multirow{4}{*}{ 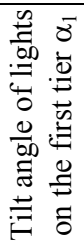 } & $25^{\circ}$ & 0.178 & 0.193 & 0.205 & 0.214 \\
\hline & $30^{\circ}$ & 0.186 & 0.202 & 0.215 & 0.225 \\
\hline & $35^{\circ}$ & 0.194 & 0.211 & 0.225 & 0.235 \\
\hline & $40^{\circ}$ & 0.203 & 0.221 & 0.236 & 0.247 \\
\hline
\end{tabular}

\begin{tabular}{|c|c|c|c|c|c|}
\hline & \multicolumn{4}{|c|}{ Tilt angle of lights on the second tier $\alpha_{2}$} \\
\hline & & $40^{\circ}$ & $45^{\circ}$ & $50^{\circ}$ & $55^{\circ}$ \\
\hline \multirow{4}{*}{ 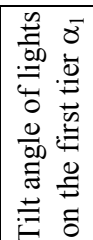 } & $25^{\circ}$ & 31 & 28 & 27 & 27 \\
\hline & $30^{\circ}$ & 28 & 25 & 23 & 20 \\
\hline & $35^{\circ}$ & 26 & 23 & 20 & 18 \\
\hline & $40^{\circ}$ & 23 & 21 & 19 & 17 \\
\hline
\end{tabular}




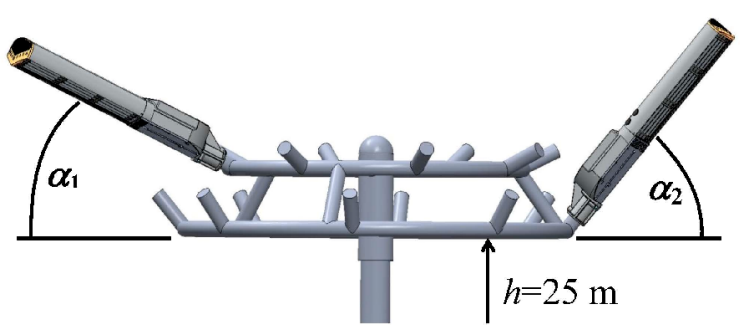

Fig. 2. Design of the two-tier corona of the high-pole lighting installation with the height $h$.

Let's define optimal angles $\alpha_{1}, \alpha_{2}$ of the lighting installation on the first and the second corona tiers. Thereto, let's calculate the main photometric parameters, namely: maximum $E_{\max }$ and middle $E_{\text {mid }}$ illuminance levels, minimum to maximum ratio $E_{\min } / E_{\max }$, and dependence of the ratio $E_{\min } / E_{\text {mid }}$ on tilt angles of lights on the first $\left(\alpha_{1}\right)$ and second $\left(\alpha_{2}\right)$ tiers. Tilt angles are altering within the range from $10^{\circ}$ to $55^{\circ}$ in increments of $5^{\circ}$. The calculation was carried out for the area $100 \times 100 \mathrm{~m}$. Our findings are presented in Table.

The key parameter among those presented in Table is the illuminance uniformity $E_{\min } / E_{\max }$ that should not be worse than 1:16. For this reason all values that don't meet this criterion are black-marked in Table.

It should be mentioned that the illuminance at $50-\mathrm{m}$ distance from the lighting installation is approximately $5 \mathrm{~lx}$, i.e. the recommended distance between poles is 90 $110 \mathrm{~m}$.

The analysis of acquired data shows that installation of lights on the first tier at the angle $\alpha_{1}=30^{\circ}$ and on the second tier at $\alpha_{2}=50^{\circ}$ provides the uniform illuminance for the area $100 \times 100 \mathrm{~m}$.

The resulting illuminance distribution is depicted in Fig. 3. According to it, the middle illuminance level is $E_{\text {mid }}=9.4 \mathrm{~lx}$, the maximum illuminance level is $E_{\max }=23 \mathrm{~lx}$, the uniformity is $E_{\min } / E_{\max }=0.090(1: 11)$.

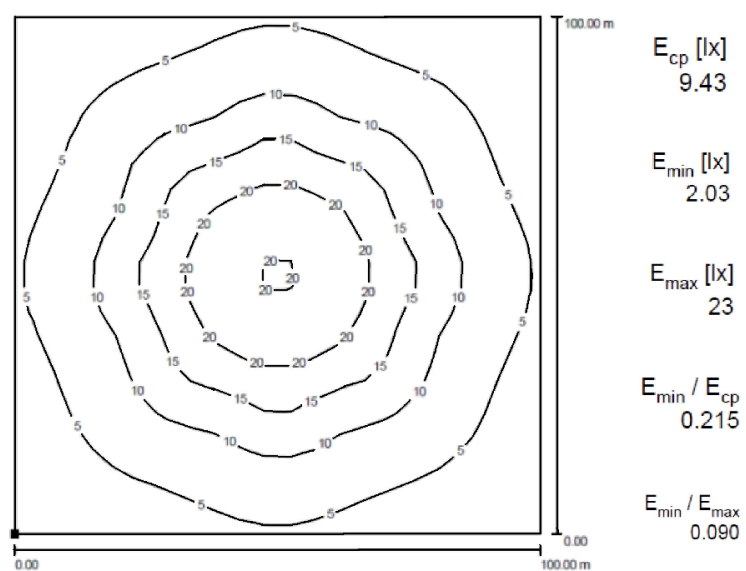

Fig. 3. Distribution of the illuminance created by two-tier lighting installation at the angles $\alpha_{1}=30^{\circ}, \alpha_{2}=50^{\circ}(h=25 \mathrm{~m})$.
The design of the corona developed to achieve the above mentioned photometric indicators is shown in Fig. 4a. The corona consists of sixteen $170 \mathrm{~W}$ LED Street Lights "Phoenix", set on two tiers. Tiers are made in the form of two metal circles of different diameters. On the upper/lower tiers, the brackets are fixed for mounting the lights. Within each circle the brackets are set in increments of $45^{\circ}$, and the upper circle is turned at $22.5^{\circ}$ relative to the lower circle. The brackets on the upper/lower tier are set at the angle $\alpha_{1}=30^{\circ} / \alpha_{2}=50^{\circ}$ relative to the horizon plane, respectively. The advantage of this design is that fixing points of outside lights are located a bit lower and farther from the center of the circle because of the bigger tilt angle. This allows getting the best location of lights relative to each other: centers of all lights are practically circumferentially spaced, different tilt angles don't provide shading.

In some cases, for example, when the high poles are attached to high-rise buildings, lighting installations with the light spot displaced relative to the place of highpole mounting are required. In these cases, lighting installations based on 9 LED Street Lights "Phoenix" (Fig. 4b) can be used. 5 lights are mounted on the lower tier $\left(\alpha_{2}=50^{\circ}\right)$, and 4 of them are on the upper tier $\left(\alpha_{1}=30^{\circ}\right)$.

Let's see the opportunities of developed lighting system by way of example of 2 model objects: tramway depot "Railway Station" \& "Airport". They are quite extended objects: with length up to $800 \mathrm{~m}$ and width up to $200 \mathrm{~m}$. The task was to provide normalized illuminance level equal to $6 \mathrm{~lx}$ [5] by using minimum quantity of $25-\mathrm{m}$ lighting installations. This task was successfully solved, and results of photometric modeling are presented in Fig. 5.
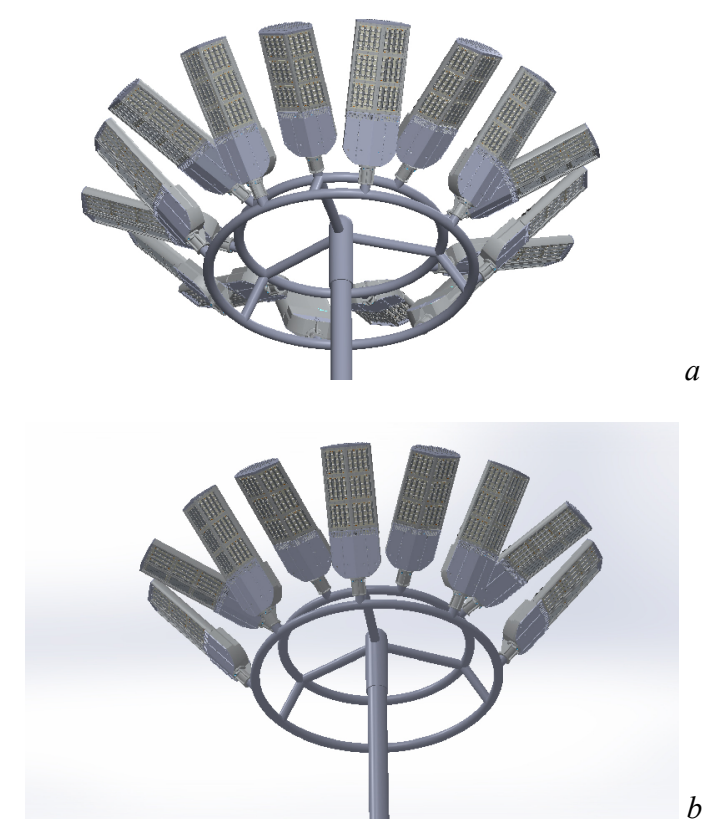

Fig. 4. High-pole lighting system based on 16 (a) and 9 (b) LED lights. 

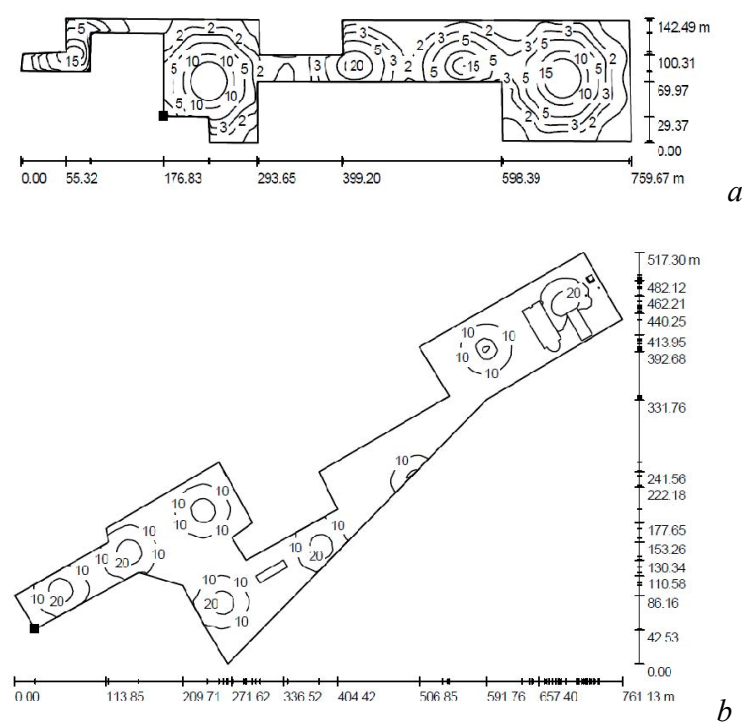

Fig. 5. Distribution of the illuminance for the model objects "Depot" (a) and "Airport" (b).

\section{Conclusion}

Thus, the obtained results enable to draw a conclusion about the principle possibility to create a high-pole LED lighting system on the basis of mass produced LED
Street Lights "Phoenix". The middle illuminance level in 1 hectare area is $9 \mathrm{~lx}$. The suggested lighting is suitable for illuminating vast parkings located close to hypermarkets and big shopping centers, as under the Technical Code of good practice [4], normalized middle horizon illuminance for open-air parkings of all categories is only $4 \mathrm{~lx}$. Fewer poles will be required in comparison with conventional lighting systems, which reduces the capital expenditure to erect the poles and expand the area for stalls.

\section{References}

1. A. Bogdanov, Experience of introduction of LED lighting systems on Russian Railways objects // Solid-state Lighting, 2(10), p. 56-58 (2011), in Russian.

2. http://www.bbeled.com

3. Russian Industry Standard OST 32120-98 "Norms of artificial illumination of railway transport objects".

4. Technical Code of good practice TKP 45-2.04-1532009 (02250) "Natural and artificial lighting. Building design standards" (in Russian).

5. Russian Industry Standard SNIP 2.05.09-90 "Tram and trolleybus lines" (in Russian). 